\title{
Skin temperature from the Thermal Infrared Sounder IASI
}

Sarah Safieddine ${ }^{1}$, Ana Claudia Parracho ${ }^{1}$, Maya George ${ }^{1}$, Filipe Aires ${ }^{2}$, Victor Pellet $^{2}$, Lieven Clarisse ${ }^{3}$, Simon Whitburn ${ }^{3}$, Olivier Lezeaux ${ }^{4}$, Jean-Noël Thépaut ${ }^{5}$, Hans Hersbach ${ }^{5}$, Gabor Radnoti ${ }^{5}$, Frank Goettsche ${ }^{6}$, Maria Martin ${ }^{6}$, Marie DoutriauxBoucher $^{7}$, Dorothée Coppens ${ }^{7}$, Thomas August ${ }^{7}$, and Cathy Clerbaux ${ }^{1,3}$

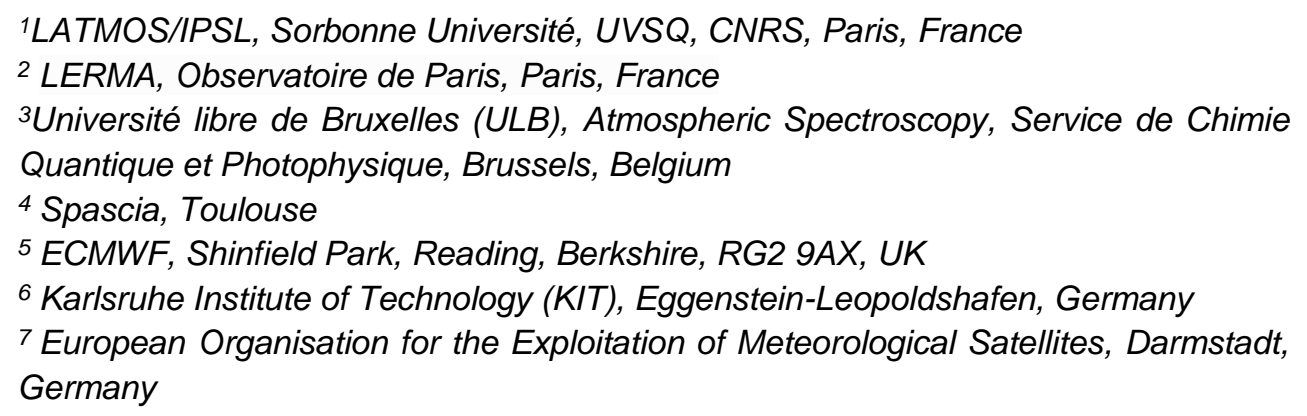

\section{Abstract}

Skin temperature ( $\left.T_{\text {skin }}\right)$ derived from infrared sensors on board satellites provides a continuous view of Earth's surface day and night and allows for the monitoring of global temperature changes relevant for climate trends. Tskin from the Infrared Atmospheric Sounding Interferometer (IASI) has not been properly exploited to date to assess its long-term spatio-temporal variability and no current homogenous $T_{\text {skin }}$ record from IASI exists. In this study, we present a fast retrieval method of $T_{\text {skin }}$ based on an artificial neural network from a set of IASI channels selected using the information theory/entropy reduction technique. We compare and validate our IASI $\mathrm{T}_{\text {skin }}$ product with that from EUMETSAT Level 2, ECMWF Reanalysis ERA5, SEVIRI land-surface temperature products, as well as ground measurements. Our results show good correlation between the IASI neural network product and the datasets used for validation, with a standard deviation between 1 and $4{ }^{\circ} \mathrm{C}$. This method can be applied to other infrared measurements, and allows for the construction of a robust $T_{\text {skin }}$ dataset, making it suitable for trend analysis.

\section{Introduction}

Land surface temperature, radiometric temperature, or as used hereafter, skin temperature $T_{\text {skin }}$ depends on the energy fluxes between the surface and the atmosphere. It is an important factor for studying the Earth's energy balance, convection at the surface, monitoring droughts and in numerical weather prediction (Goldberg et al., 2003; Zhou et al., 2003; Rhee et al., 2010). Although in situ observations play a major role in measuring relevant climate change indicators, local measurements are sparse and unevenly distributed. Global view observations are now routinely available from remote sensors on satellites, providing data from which 
climate variables, such as $T_{\text {skin }}$ can be derived using appropriate retrieval methods. The World Meteorological Organization (WMO) Global Climate Observing System (GCOS) program, aims at identifying requirements for the global climate monitoring system. It recommends 54 key variables (https://gcos.wmo.int/en/essential-climatevariables/), called Essential Climate Variables (ECVs), as the atmospheric, land, and ocean components of this monitoring system (GCOS, 2017). Near-surface temperature and skin temperature are both ECVs. In the thermal infrared spectral range, satellites do not measure the well-known thermodynamic near-surface air temperatures $\left(\mathrm{T}_{2 \mathrm{~m}}\right)$; instead, they measure the skin temperature. It is called "skin" temperature since it corresponds to the radiation emitted from depths less or equal to the penetration depth at a given wavelength (Becker and Li, 1995), which can be as small as 10-20 micrometers at the ocean surface (McKeown et al., 1995). The relationship between $T_{\text {skin }}$ and $T_{2 m}$ is complex: differences between $T_{\text {skin }}$ and $T_{2 m}$ can reach several to ten or more degrees under cloud-free, low wind speed conditions, and is usually smaller under cloudy conditions or when solar insolation is low (Prigent et al., 2002; 2003; Good, 2016).

Satellite retrievals of skin temperatures are available from a variety of polar-orbiting and geostationary platforms carrying microwave and infrared sensors, such as the Spinning Enhanced Visible and Infrared Imager (SEVIRI) onboard the geostationary Meteosat Second Generation (Trigo et al., 2008), the Advanced Very High Resolution Radiometer (AVHRR) sensors onboard the different NOAA polar orbiting platforms and more recently on the suite of Metop satellites (Jin, 2004), the Moderate Resolution Imaging Spectroradiometer (MODIS) on board of the Terra and Aqua satellites (Wan and Li, 1997), the Atmospheric InfraRed Sounder (AIRS, Ruzmaikin et al., 2017), on board the Aqua satellite, and from the Infrared Atmospheric Sounding Interferometer (IASI) on board the three Metop satellites since 2007, 2012 and 2018 (Siméoni et al., 1997; Blumstein et al., 2004; Hilton et al., 2012).

With a polar orbit, IASI on Metop revisits all points on the Earth's surface twice a day at around 9:30 am and 9:30 pm local time. IASI is designed for numerical weather prediction, climate research and atmospheric composition monitoring (Collard et al., 2009; Clerbaux et al., 2009; Hilton et al., 2012). It measures radiances in the thermal infrared spectral range between 645 and $2760 \mathrm{~cm}^{-1}$ corresponding to 8461 spectral channels, every $0.25 \mathrm{~cm}^{-1}$, with an instrument response function of $0.5 \mathrm{~cm}^{-1}$ halfwidth after apodization. With more than eleven years of data that are now readily available, the instrument provides more than 1.2 million radiance spectra per day with a footprint on the ground of $12 \mathrm{~km}$ diameter pixel (at nadir). IASI scenes are reduced by around one third when clear sky filtering ( $<10 \%$ cloud coverage) is applied, a necessity for accessing information at the surface. IASI has been used for atmospheric composition sounding, allowing near-real-time mapping of chemical species and aerosols, contributing to air traffic safety, and improving the understanding of atmospheric transport processes (e.g., Coheur et al., 2009; Clarisse et al., 2011; Clerbaux et al., 2015). 
The interest in exploiting highly spectrally resolved IASI data to study climate variability has been previously highlighted (Clerbaux et al., 2003; Brindley et al., 2015; Smith et al., 2015). However, relatively little has been done to generate systematic records for climate variables with IASI, although the spectral signature of climate variability and $T_{\text {skin }}$ anomalies have been studied for similar instruments (e.g. AIRS, Brindley et al., 2016; Susskind et al., 2019). The instrument is relatively new (radiances are provided since July 2007) and the climate community is still not fully aware of its potential. It is also computationally demanding to systematically process the large amount of data generated by the instrument. However, since IASI is planned for flying at least 18 years, with the 3 instruments built at the same time and flying in constellation, continuity and stability are insured, and the potential of constructing a long-term climate data record is becoming evident. In addition, it is worth noting that the long-term continuation of the program is also guaranteed, as the new generation of Infrared Atmospheric Sounding Interferometers (IASI-NG) (Clerbaux and Crevoisier, 2013; Crevoisier et al., 2014), will be launched on three successive Metop - Second Generation satellites within the 2022-2040 timeframe.

IASI data are disseminated by EUMETSAT (EUropean organization for the exploitation of METeorological SATellites) (Klaes et al., 2007). It processes a $T_{\text {skin }}$ product from the series of the Metop satellites for day-to-day meteorological applications. This $T_{\text {skin }}$ product is derived from IASI upwelling radiances but also relies on other microwave instruments on board of Metop, particularly for cloudy scenes. This dataset is not homogeneous in time, neither for the Level 1C (L1C), radiances, nor for Level 2 (L2) operational products (e.g. temperature, humidity, cloud cover, etc.). Changes occurred with evolving versions of the processing algorithm (EUMETSAT, 2017a; EUMETSAT, 2017b), with the algorithm mostly stable after 2016. The Metop-A L1C record has been reprocessed back in time at EUMETSAT for the period 2007-2017, and is used in this work, and will be publically available in summer 2019. L1C data after 2017 are not reprocessed because they are assumed to be up to date. The Level 2 series has not yet been reprocessed back in time, which complicates the construction of a homogeneous $T_{\text {skin }}$ data record from IASI.

More generally, high volumes of data resulting from IASI present many challenges in data transmission, storage, and assimilation. One of the simplest methods for reducing the data volume is channel selection. The goal of this study is to present a fast and reliable method developed to retrieve $T_{\text {skin }}$ from radiances using a limited set of radiances from the newly reprocessed IASI L1C data record in the thermal infrared in order to have a consistent and homogeneous product covering the whole IASI sounding period.

The challenge is therefore to find the optimal set of channels from which skin temperature can be retrieved. In the following section 2, we present an approach based on entropy reduction (Rodgers, 1996; Collard, 2007) from which we deduce a set of 100 channels most sensitive to skin temperature from the IASI 8461 channels. The dataset is then used to retrieve skin temperature from IASl's cloud-free 
radiances using an artificial neural network (ANN). In section 3 we validate the product and we conclude this paper with a discussion in section 4 of the current challenges in validation and comparison of different $T_{\text {skin }}$ products.

\section{Data and methods}

\subsection{Choice of IASI spectral window for $T_{\text {skin }}$ retrieval}

IASI uses three detectors to fully cover the spectral range that extends from 645 to $2760 \mathrm{~cm}^{-1}$ (15.5 to $\left.3.62 \mu \mathrm{m}\right)$ with no gaps. To understand the spectral window that must be used for $T_{\text {skin }}$ retrieval, we show in Figure 1, upper panel, a IASI typical cloud-free spectra, with the corresponding Jacobian (the sensitivity of the IASI brightness temperature to the skin temperature), as well as Signal to Noise Ratio (SNR), and radiometric noise. The recorded spectrum, with an example shown in red in the upper panel of Figure 1, in brightness temperature units, exhibits signatures associated with spectroscopic absorption/emission lines of molecules present along the optical path between the Earth's surface and the satellite detectors. From these spectra, geophysical data such as temperature profiles and atmospheric concentrations of trace gases can be derived from selected spectral windows. Channels that are candidates for $\mathrm{T}_{\text {skin }}$ retrieval are therefore located in spectral windows with little interference from other absorbing/emitting molecules, and are also those where the $T_{\text {skin }}$ Jacobians (blue line in upper panel) are the highest. These are the spectral ranges before and after the ozone band, i.e., $800-1040 \mathrm{~cm}^{-1}$ and 1080 $1150 \mathrm{~cm}^{-1}$, the small spectral window after the water vapor continuum at $\sim 2150 \mathrm{~cm}^{-1}$ and the spectral range $>2400 \mathrm{~cm}^{-1}$.

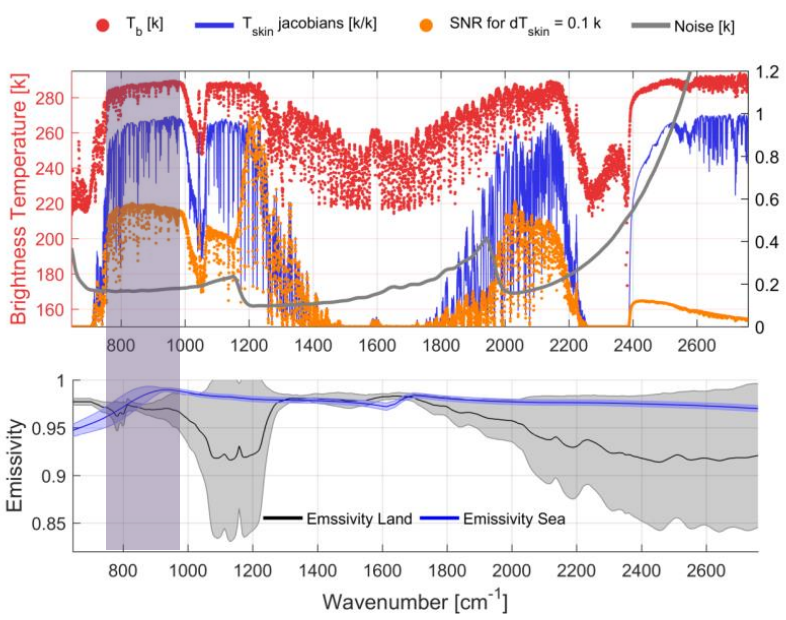

Figure 1. Upper panel: brightness temperatures for a random cloud-free spectrum (red). On the right axis, $\mathrm{T}_{\text {skin }}$ Jacobians in $\mathrm{k} / \mathrm{k}$ (dark blue), signal-to-noise ratio obtained for a variation of $T_{\text {skin }}$ of $0.1 \mathrm{k}$ (orange), and IASI radiometric noise spectrum (grey), calculated using RTTOV (Saunders et al., 2018). Lower panel: Average emissivity over land (black), and sea (blue), with the corresponding standard 
deviation in shaded colors around the lines. The shaded vertical strip shows the spectral window used for $\mathrm{T}_{\text {skin }}$ retrievals in this study.

The window $>2400 \mathrm{~cm}^{-1}$, as well as that around $\sim 2150 \mathrm{~cm}^{-1}$ may be contaminated by solar radiation during the day. In terms of SNR, the very important values of the radiometric noise at $>2400 \mathrm{~cm}^{-1}$ induces a low value of the SNR. The spectral band at $\sim 2150 \mathrm{~cm}^{-1}$ presents a slightly weaker performance than the spectral ranges around the ozone absorption band. These two spectral bands $\left(\sim 2150\right.$ and $>2400 \mathrm{~cm}^{-}$ $\left.{ }^{1}\right)$ are therefore not critical for the $T_{\text {skin }}$ retrieval and are discarded.

The lower panel of Figure 1 shows the average emissivity over land (in black) and sea (in blue). Emissivity is needed to calculate $T_{\text {skin from the radiative transfer }}$ equation. In this work, we want to use a method without prior assumption on emissivity. Nevertheless, we should be careful with our choice of channels' emissivity in our selected spectral window. We can see that on the right of the ozone band, around $1100-1200 \mathrm{~cm}^{-1}$, the variability of the emissivity, especially over land is much more important than the window between 750 and $970 \mathrm{~cm}^{-1}$, shown in the shaded rectangle in Figure 1, where also the noise is smaller, and the SNR higher. This makes this spectral window the best candidate for $T_{\text {skin }}$ retrieval.

\subsection{Channel Selection based on Entropy Reduction}

We use an iterative method where channels are selected based on their ability to reduce the uncertainty of retrieving temperature. It was proposed by Rodgers (1996, 2000), evaluated for IASI by Rabier et al. (2002) and applied by Collard et al. (2007) to Numerical Weather Prediction (NWP).

The method has been rigorously studied and relies on evaluating the impact of the addition of single channels on a theoretical retrieval based on a figure of merit, such as the Entropy Reduction (ER), used in this study, and defined as follows:

$$
E R=\frac{1}{2} \log _{2}\left(\frac{B}{A}\right)
$$

$E R$ measures the probabilities of the ensemble of possible states in the retrieval, and is maximal if all the states have an equal probability. The lower the entropy of the ensemble, the better the retrieval. The channel that reduces this entropy emphasizes a particular state of the retrieval. Entropy reduction is a metric derived from information theory. In Eq. (1), $A$ is the analysis-error covariance matrix, and $B$ is the background/a priori error covariance matrix, with:

$$
A=\left(B^{-1}+H^{T} R^{-1} H\right)^{-1}, \quad \text { Eq. (2) }
$$

Where $H$ is the Jacobian matrix of $\mathrm{T}_{\text {skin }}$ and $R$ the covariance matrix of instrumental and radiative transfer noises. "External variables" such as water vapor or ozone can 
contaminate a given candidate $\mathrm{T}_{\text {skin }}$ channel by absorbing in the targeted spectral range. This might affect the selection, and introduces an error that should be added to the $A$ matrix (Aires et al. 2016, Pellet and Aires, 2016). If those errors were not included in the background $B$ matrix, the quality of the selected channels might be artificially over-estimated. When this contaminating effect is defined explicitly, Eq. (2) is updated to:

$$
A_{V^{-1}}=B_{V}^{-1}+H_{V}^{t} \cdot\left(R+H_{v} \cdot B_{v} \cdot H_{v}^{t}\right)^{-1} \cdot H_{V} \quad \text { Eq. (3) }
$$

Where $V$ is the variable to be retrieved $\left(T_{\text {skin }}\right)$ and $v$ is the external variable (e.g. ozone or water vapor). This equation is valid by making some assumptions, in particular that no correlation between $V$ and $v$ exists and that the impact of this external variable contamination on the channel is an error with Gaussian distribution with covariance matrix $H_{v}^{t} \cdot B_{v} \cdot H_{v}$.

In most channel selection analyses, the errors from external variables (such as that of relative humidity or ozone) are not taken into account in the measurement of the information content of the candidate channel. Collard (2007) attempted to take into account the effects of trace gases not included in the radiative transfer simulation by inflating the observation errors for channels that showed sensitivity to the missing species. A more complete approach was adopted by Ventress and Dudhia (2014), who used climatological variability of atmospheric constituent species to model their effect on the radiances during the channel selection process.

In this work, we explicitly consider the contamination effect in the selection process of dedicated $T_{\text {skin }}$ related-channels. This refined methodology improves the representation of contamination effects from atmospheric species and therefore the reliability of the background error covariance matrix $B$. This matrix $B$ characterizes the quality of the a priori information and varies in space and time in order to account for its complex state-dependence. For this work, we derive a Gaussian $B$ matrix as: $B=\operatorname{Cov}(x, y)=\operatorname{Corr}(x, y) \cdot \sigma(x) \cdot \sigma(y)$, where $\sigma$ is the standard deviation of each of

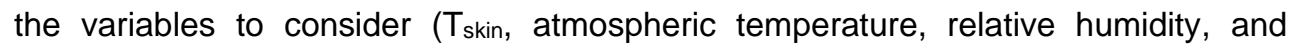
ozone) at the vertical level $\mathrm{x}$ and $\mathrm{y}$. An uncertainty of $\sigma=2 \mathrm{k}$ is chosen for $\mathrm{T}_{\text {skin }}$ as done in the study by Collard (2007). The covariance and correlation matrices of the background errors for relative humidity and ozone are calculated based on the widely used assumption that humidity (or ozone) error correlation between the vertical layers is close to the actual associated humidity (or ozone) correlation. We choose to have the covariance matrices $B$ for humidity and ozone based on the raw humidity and ozone correlation matrices, and an error variance $\left(\sigma^{2}\right)$ of $20 \%$ for humidity, and $30 \%$ for ozone on each vertical atmospheric layer. As humidity and ozone can impact $\mathrm{T}_{\text {skin }}$ channel selection, error along the vertical is needed for $T_{\text {skin }}$ retrieval.

An iterative method (Rodgers, 1996) is used to forwardly select the most informative channels. In order to speed up the computations, an efficient algorithm was 
developed assuming that the observation errors are uncorrelated between channels. However, as the IASI radiances are apodized, and thus have highly-correlated errors between adjacent channels, a channel is not selected if its immediate neighbor is already chosen (Collard, 2007).

The iterative procedure is initialized with $A_{0}=B$, and the Jacobian $H$ (which is constant during the iteration) is normalized with the instrumental noise covariance matrix $R$, as follows: $H^{\prime}=R^{-1 / 2} H$.

According to Rodgers (1996), the updated analysis error covariance matrix at each iteration step $i$ can be calculated from the previous step $i-1$ as follows:

$$
A_{i}=A_{i-1}-\frac{\left(A_{i-1} h^{\prime}\right)\left(A_{i-1} h^{\prime}\right)^{T}}{1+\left(A_{i-1} h^{\prime}\right)^{T} h^{\prime}}
$$

Where $h^{\prime}$ is the column vector equal to the row of $H^{\prime}$ for the candidate channel.

The ER change between two iterations can now be written as:

$$
\delta E R=\frac{1}{2} \log _{2}\left(1+h^{\prime T} A_{i-1} h^{\prime}\right)
$$

At each step, the channel that has the largest information content (measured as a reduction of the entropy of the corresponding $T_{\text {skin }}$ retrieval when the candidate channel is used) is selected, given the information content of the previously selected channel(s). The channel selection starts with no channel selected, and sequentially chooses the channel with the highest information content in complement to the information from all the previously selected channels.

The spectra and Jacobians used in this study were simulated using the last version of the Optimum Spectral Sampling (OSS) radiative transfer model (Moncet et al., 2008), using the Thermodynamic Initial Guess Retrieval (TIGR3) database (Chevallier et al., 1998), and more detailed description on the atmospheric profiles, the radiative transfer code, and the Jacobians, can be found in Pellet and Aires (2018).

Here, a channel selection is only performed over the spectral window of $\mathrm{T}_{\text {skin }}$ retrieval as was discussed in section 2.1, and is shown in Figure 2. The IASI spectral window was divided into 100 spectral subsets and a channel selection was applied to each. Using this method, we selected the best 100 channels in terms of information content and the resulting selection is listed in Table 1 and presented in Figure 2. The figure shows that most of the selected channels are between 760 and $980 \mathrm{~cm}^{-1}$. However, few channels are also selected for wavenumbers $<760 \mathrm{~cm}^{-1}$ since in this part of the spectrum, the atmospheric vertical levels are very correlated to one another and therefore information on the surface exists in these channels.

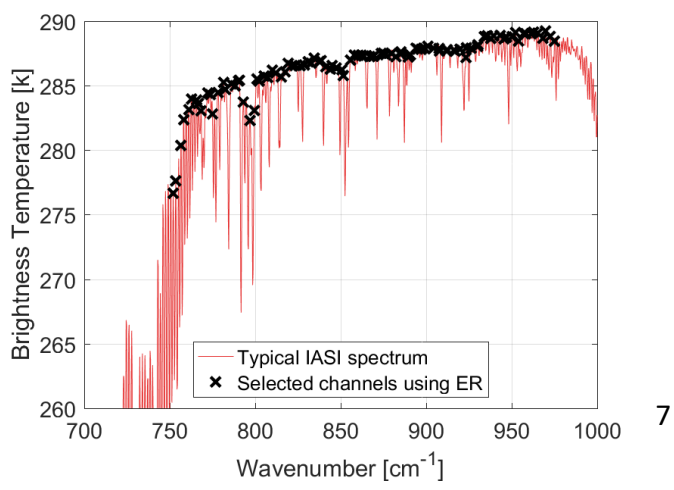

Figure 2. The location of the 100 selected channels using the ER method displayed on a IASI spectrum. 
Table 1. The 100 channels used for $T_{\text {skin }}$ retrieval selected using the Entropy Reduction (ER) method. Channels are sorted from the highest to the lowest information content (top to bottom and left to right).

\begin{tabular}{|rr|rr|rr|rr|}
\hline $\begin{array}{l}\text { Chann } \\
\text { el }\end{array}$ & $\begin{array}{r}\text { Wavenum } \\
\text { ber }\left(\mathrm{cm}^{-1}\right)\end{array}$ & $\begin{array}{l}\text { Clann } \\
\text { el }\end{array}$ & $\begin{array}{r}\text { Wavenum } \\
\text { ber } \\
\left(\mathrm{cm}^{-1}\right)\end{array}$ & $\begin{array}{l}\text { Chann } \\
\text { el }\end{array}$ & $\begin{array}{l}\text { Wavenum } \\
\text { ber }\left(\mathrm{cm}^{-1}\right)\end{array}$ & $\begin{array}{l}\text { Chann } \\
\text { el }\end{array}$ & $\begin{array}{l}\text { Wavenum } \\
\text { ber }\left(\mathrm{cm}^{-1}\right)\end{array}$ \\
\hline 1300 & 969.75 & 1038 & 904.25 & 853 & 858.00 & 682 & 815.25 \\
\hline 1282 & 965.25 & 1100 & 919.75 & 984 & 890.75 & 582 & 790.25 \\
\hline 1249 & 957.00 & 1001 & 895.00 & 862 & 860.25 & 630 & 802.25 \\
\hline 1272 & 962.75 & 1321 & 975.00 & 771 & 837.50 & 625 & 801.00 \\
\hline 1254 & 958.25 & 1209 & 947.00 & 759 & 834.50 & 574 & 788.25 \\
\hline 1294 & 968.25 & 1069 & 912.00 & 752 & 832.75 & 584 & 790.75 \\
\hline 1230 & 952.25 & 997 & 894.00 & 797 & 844.00 & 547 & 781.50 \\
\hline 1164 & 935.75 & 1070 & 912.25 & 745 & 831.00 & 551 & 782.50 \\
\hline 1267 & 961.50 & 921 & 875.00 & 775 & 838.50 & 565 & 786.00 \\
\hline 1194 & 943.25 & 962 & 885.25 & 801 & 845.00 & 516 & 773.75 \\
\hline 1179 & 939.50 & 1051 & 907.50 & 714 & 823.25 & 510 & 772.25 \\
\hline 1222 & 950.25 & 940 & 879.75 & 706 & 821.25 & 593 & 793.00 \\
\hline 1311 & 972.50 & 916 & 873.75 & 698 & 819.25 & 534 & 778.25 \\
\hline 1086 & 916.25 & 1114 & 923.25 & 844 & 855.75 & 484 & 765.75 \\
\hline 1157 & 934.00 & 950 & 882.25 & 726 & 826.25 & 472 & 762.75 \\
\hline 1172 & 937.75 & 869 & 862.00 & 810 & 847.25 & 488 & 766.75 \\
\hline 1142 & 930.25 & 1237 & 954.00 & 736 & 828.75 & 494 & 768.25 \\
\hline 1203 & 945.50 & 926 & 876.25 & 824 & 850.75 & 466 & 761.25 \\
\hline 1018 & 899.25 & 961 & 885.00 & 691 & 817.50 & 619 & 799.50 \\
\hline 1141 & 930.00 & 875 & 863.50 & 669 & 812.00 & 609 & 797.00 \\
\hline 1009 & 897.00 & 979 & 889.50 & 661 & 810.00 & 521 & 775.00 \\
\hline 1089 & 917.00 & 889 & 867.00 & 786 & 841.25 & 454 & 758.25 \\
\hline 1115 & 923.50 & 899 & 869.50 & 827 & 851.50 & 447 & 756.50 \\
\hline 1025 & 901.00 & 897 & 869.00 & 642 & 805.25 & 435 & 753.50 \\
\hline 1126 & 926.25 & 1052 & 907.75 & 650 & 807.25 & 429 & 752.00 \\
\hline
\end{tabular}

\subsection{Artificial Neural Network for $\mathbf{T}_{\text {skin }}$ retrievals}

Artificial neural networks (ANN) method is used to approximate the complex radiative transfer function that maps the radiances to skin temperature. The training dataset is constructed out of clear-sky (cloud cover $<10 \%$ ) Level 1C (L1C) IASI radiances over the 100 channels selected in section 2.2. We train our ANN with these IASI radiances but test two different datasets as output/target. In the first, we use the $T_{\text {skin }}$ from the ERA5 reanalysis (Copernicus Climate Change Service, 2017) as output/target. $T_{\text {skin }}$ is very sensitive to surface properties, which depend on local meteorological conditions (Good, 2016). To this end, a few dedicated ERA5 experiments were performed at ECMWF at a 12-minute time-step (as opposed to the publicly released 
hourly $T_{\text {skin }}$ product), each spanning a couple of days. The aim of these experiments is to increase the temporal resolution and therefore increase the performance of the neural network obtained. Four days in January and June 2018 are used for the training to represent seasonality. We interpolate ERA5 space/time grid to IASI's observations (at 9:30 AM and PM local time). We provide more information on the ERA5 reanalysis in section 3 . The resulting training dataset is formed out of around $5.9 \times 10^{5}$ scenes. In the second training, we use EUMETSAT L2 $\mathrm{T}_{\text {skin }}$ product as target. EUMETSAT $T_{\text {skin }}$ is derived from Metop observations and the IASI instrument. They are therefore collocated in space and time. Since major and minor updates on the processing algorithms of the L1C and L2 EUMETSAT product took place in the past 10 years (EUMETSAT, 2017a; 2017b), the ANN training in this study uses a recent and coherent year, 2018. To represent the seasonal variability, scenes from January $1^{\text {st }}$, April $1^{\text {st }}$, July $1^{\text {st }}$, and October $1^{\text {st }} 2018$ are used. The resulting training dataset is formed out of around $9 \times 10^{5}$ scenes for EUMETSAT. More information on the EUMETSAT Tskin product is provided in section 3 .

Since IASI has more frequent overpasses at the poles (given its polar orbit), a weighting function is applied to equally distribute the number of scenes around the globe. The training is done using mini-batches with a maximum of 10.000 epochs to train. The ANN has 2 hidden layers with 4 nodes, and a network training function that updates weight and bias values according to Levenberg-Marquardt optimization.

The neural network learns how to associate any set of radiances to a corresponding skin temperature. The feasibility of using $A N N$ to $T_{\text {skin }}$ retrieval has been shown for instance by Aires et al. (2002) for IASI, and has also been performed to tackle various problems in atmospheric remote sensing (Blackwell and Chen, 2009; HadjiLazaro et al., 1999; Whitburn et al., 2016; Van Damme et al., 2017). In the following "TANN" refers to the product developed in this study using artificial neural networks from IASI radiances.

Figure 3 shows the training results when the TANN is compared with the TERA5 dataset is used for the training, and in Figure 4 when the TEUMETSAT is used for the training. We achieve a good agreement with a standard deviation of 2.2 and 1.6 respectively and a correlation coefficient close to 1 . The largest differences are for points located near the poles and at high altitudes. One of the reasons behind the discrepancies in mountainous regions is the general under-representation of the orography in global numerical weather prediction (NWP) and climate models, due to their limited horizontal resolution. Orographic features exert drag and its correct representation in models is extremely challenging. The incorrect representation of drag might lead to errors in simulating surface properties and might be responsible for the bias seen in mountainous regions (ECMWF, 2016). Moreover, with altitudes and variable emissivity in these regions, the neural network fails (to some extent) to properly map the altered radiances due to surface inhomogeneity into a correct skin temperature. 
Figures $3 \mathrm{~b}$ and $4 \mathrm{~b}$ also show how the difference between the two products is lowest over the sea, which can suggest the robustness of this method, in particular for sea skin temperature analysis.
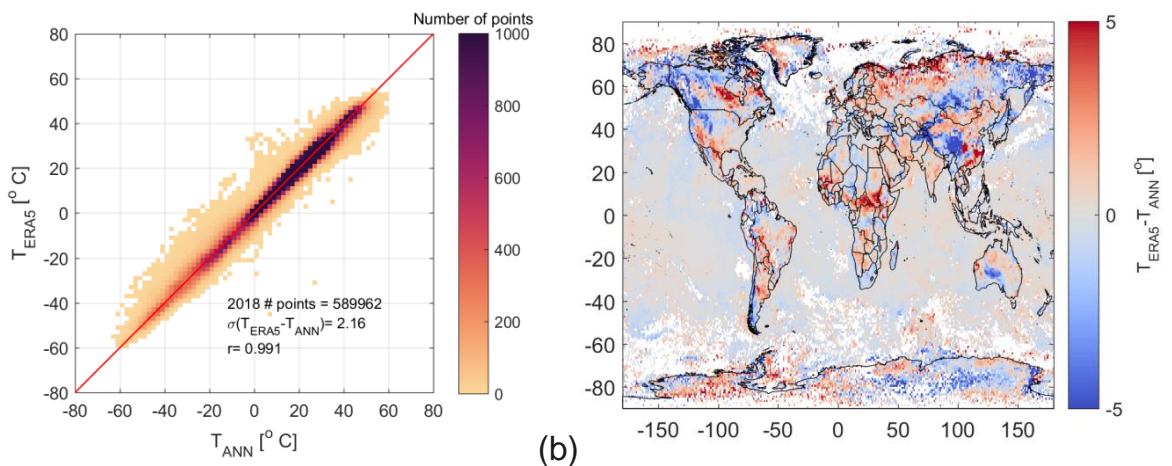

(a)

Figure 3. Neural network performance when trained with ERA5 data: (a) scatterplot and correlation, (b) gridded and averaged spatial comparison.
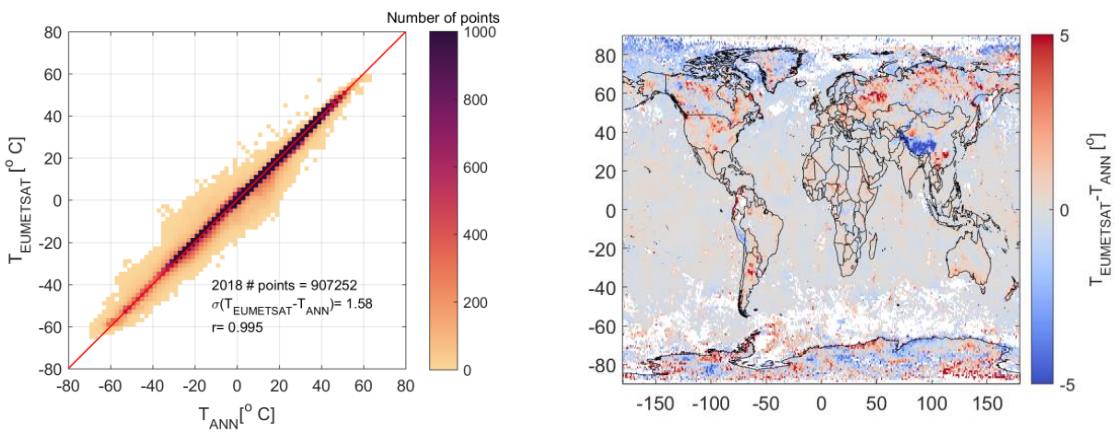

Figure 4. Neural network performance when trained with EUMETSAT data: (a) scatterplot and correlation, (b) gridded and averaged spatial comparison.

\subsection{Datasets used for validation}

We compare the TANN from the two training datasets to the EUMETSAT L2 product, the ECMWF ERA5 reanalysis, the SEVIRI satellite retrieval, and ground observations. We described each briefly hereafter.

\subsubsection{EUMETSAT $T_{\text {skin }}$ product}

Meteorological L2 data from EUMETSAT (August et al., 2012) are provided for nearly all IASI observations by deriving $T_{\text {skin }}$ primarily from IASI for cloud-free scenes and using the Advanced Microwave Sounding Unit (AMSU), and the Microwave Humidity 
Sounder (MHS) for cloudy scenes (EUMETSAT, 2017a; 2017b). AMSU and MHS are multi-channel microwave radiometers, which measure radiances in 15 and 5 discreet frequency channels respectively, and provide information on various aspects of the Earth's atmosphere and surface. They both can be used for cloud-contaminated scenes, since they are synchronized with IASl's scanning. The algorithm is based on optimal estimation. Since the algorithm uses on instruments on board of Metop, the IASI ANN cloud-free radiances used in this study are also co-localized in space and time.

\subsubsection{ERA5 $T_{\text {skin }}$ product}

In the framework of the ECMWF latest reanalysis (ERA5) (Hersbach and Dee, 2016; Hersbach et al., 2018; Copernicus Climate Change Service, 2017), skin temperature is defined as the temperature of the surface at radiative equilibrium. It is derived from the surface energy balance within the land model in ERA5 and no assimilation of surface skin temperature observations takes place. Radiances on the other hand, are assimilated. The surface energy balance is satisfied independently for each tile by calculating its skin temperature. The skin layer represents the vegetation layer, the top layer of the bare soil, or the top layer of the snow pack. In order to calculate the skin temperature, the surface energy-balance equation is linearized for each tile leading to an expression for the skin temperature (ECMWF, 2016). Over the ocean, the sea surface temperature (SST) is specified from an analysis provided by the Operational Sea Surface Temperature and Ice Analysis (OSTIA, McLaren et al., 2016) from September 2007 and prior to that date from the Met Office Hadley Centre HadISST2 product (Hirahara et al., 2016). The SST analysis is a blend of satellite retrievals and in situ observations from ships, and ensures a detailed horizontal distribution from satellite data anchored to the sparse ship observations. The resulting SST fields are therefore calibrated as if they are ship observations and therefore they represent bulk SST fields (i.e. measured a few meters deep). Since the ocean skin temperature $(<1 \mathrm{~mm}$ thickness) might be cooler than the SST because of the turbulent and long wave radiative heat loss to the atmosphere, parameterizations of different near surface ocean effects are included in the code (ECMWF, 2016).

\subsubsection{SEVIRI Tskin product}

The Spinning Enhanced Visible and Infrared Imager (SEVIRI) onboard the geostationary Meteosat Second Generation (MSG) satellite scans the Earth surface every $15 \mathrm{~min}$ and provides observations in 12 spectral channels with a sampling distance of $3 \mathrm{~km}$ at nadir. MSG's nominal position at $0^{\circ}$ longitude and SEVIRI's large field of view (up to $80^{\circ}$ zenith angle) allows for frequent observations of a wide area encompassing Africa, most of Europe and part of South America (Schmetz et al., 2002). 
The land surface temperature (LST) product (LSA-001) used for validation here (Trigo et al., 2011; Freitas et al., 2010) is retrieved by the EUMETSAT Land Surface Analysis Satellite Application Facility (LSA SAF) with the generalized split-window method, which requires land surface emissivity as input data. IASI and SEVIRI data are spatially co-located when observations from each instrument are less than 5 minutes apart, and within 0.25 degrees in longitude and latitude.

\subsubsection{Ground observations}

The ground observations are from Gobabeb wind tower, Namibia $\left(23.551^{\circ} \mathrm{S} 15.051^{\circ}\right.$ E, location shown in Figure 7, Göttsche et al., 2016). Gobabeb station is located on the large and homogenous Namib gravel plains (Göttsche and Hulley, 2012). Göttsche et al. (2013) showed that the station $T_{\text {skin }}$ is representative for an area of several $100 \mathrm{~km}^{2}$, making it suitable for validation with satellite measurements. $T_{\text {skin }}$ is obtained once per minute with the station's core instrument, an infrared precision radiometer (Heitronics KT15.85 IIP) measuring radiances between 9.6 and $11.5 \mu \mathrm{m}$. The temperature resolution is given as $0.03 \mathrm{~K}$ with an uncertainty of $\pm 0.3 \mathrm{~K}$ over the relevant range, and high stability with a drift of less than $0.01 \%$ per month (Goettsche et al., 2013).

\section{Results}

To validate the TANN product, the month of June 2016 is chosen. Since we train our neural network with 2018 data, 2016 is a good choice and data is readily available for this year. TANN is calculated from the two ANNs obtained in section 2 by applying it to each set of 100 radiances retrieved from IASI for all cloud-free observations in June 2016.

\subsection{Validation of the TANN obtained from the ERA5 neural network}

Figure 5 shows the comparison of the TANN IASI obtained from the training of IASI radiances with ERA5 12-minute data. We start by performing the validation with the EUMETSAT, ERA5, and SEVIRI Tskin datasets. The upper panel shows the correlation plots, superimposed with the average difference by latitude in red. $T_{\text {ANN }}$ from IASI compares best with the EUMETSAT $\mathrm{T}_{\text {skin }}$ product (standard deviation $\sigma=1.83^{\circ} \mathrm{C}$ ), which is plausible since it is also obtained from IASI radiances. Comparison with ERA5 also shows a correlation close to 1 , and $\sigma=2.17^{\circ} \mathrm{C}$. The largest differences for both EUMETSAT and ERA5 products are found around the poles, which are probably due to the sensitivity of radiances to surface properties and to orography-related physical processes in the ECMWF model as previously discussed. Moreover, ERA5 data are at $0.25^{\circ} \times 0.25^{\circ}$ resolution (native horizontal resolution of ERA5 is $\sim 31 \mathrm{~km}$ ) and are interpolated to the center of the IASI pixel observation, which might correspond to a different surface type and might lead to differences in temperatures. For the comparisons between TANN IASI and $T_{\text {skin }}$ 
SEVIRI a standard deviation of $\sigma=3.78 \mathrm{~K}$ is determined with the largest differences over the Arabian Peninsula. For large viewing angles, in particular near the edge of the Meteosat disk (such as the Arabian Peninsula), the uncertainty of SEVIRI Tskin is high (Freitas et al., 2010). A study by Trigo et al. (2015) reported similar to larger cool biases in the rest of the domain between the ECMWF model data and SEVIRI, especially over semiarid regions, such as North Africa, Sahara, and Namibia. In the rest of the domain, the two datasets agree reasonably well.
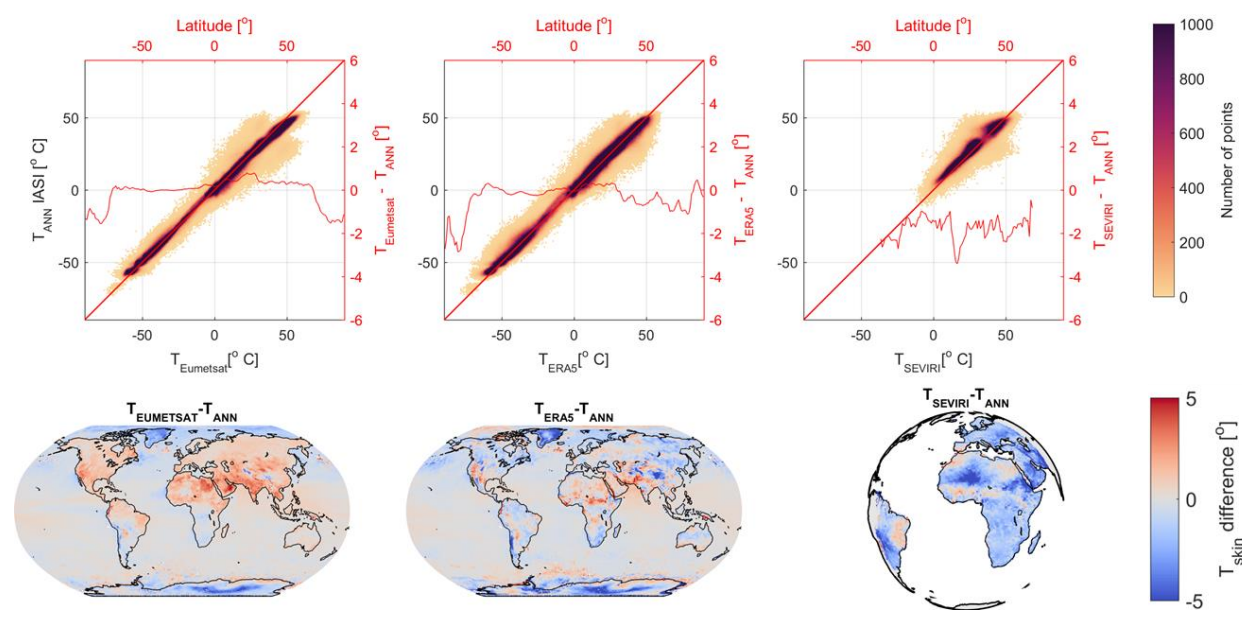

Figure 5. Validation of the $T_{\text {skin }}$ ANN product (TANN) from the neural net training of IASI radiances with ERA5, with products from EUMETSAT, ERA5 and SEVIRI, for June 2016. Upper panel: correlation plots weighted with the number of co-localized observations during one month. Lower panel: gridded and averaged spatial difference $\left[T-T_{A N N}\right]$. For day + night data: $\sigma\left(T_{\text {EUMETSAT }}-T_{\text {ANN }}\right)=1.83, \sigma\left(T_{\text {ERA5 }}-\right.$ $\left.T_{\text {ANN }}\right)=2.17, \sigma\left(T_{S E V I R I}-T_{A N N}\right)=3.78$. The total number of points for the global comparison is $8.2 \times 10^{6}$ and $4.96 \times 10^{5}$ for the SEVIRI comparison.

While this paper focuses on validating IASI TANN, inter-comparisons between the different products (ERA5 with EUMETSAT L2 or EUMETSAT L2 with SEVIRI, etc.) are valuable for assessing their differences. Figure 6 shows the box plot of these inter-comparisons, with the absolute bias and standard deviation of the comparison between the products. We perform inter-comparisons for day- and night-times separately. At nighttime, the absence of solar illumination allows a direct comparison of the skin temperature retrieved or modelled from different instruments. It can be seen that the TANN product developed in the framework of this study is within the range of biases among the other products comparison. 

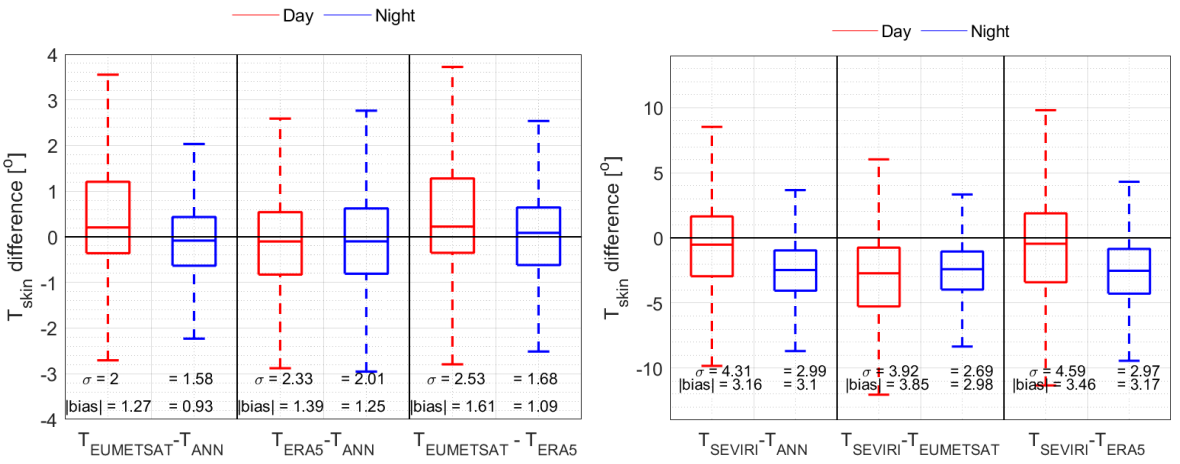

Figure 6: Boxplot of the June 2016 inter-comparison of the different $T_{\text {skin }}$ products used in this study. Since the matching with SEVIRI leads to fewer co-localized data points covering the SEVIRI disk, they are shown on a separate figure on the right. The central mark indicates the median, and the bottom and top edges of the box indicate the 25th and 75 th percentiles.

Figure 6 shows that the night observations of TANn, Teumetsat and Tera5 seem to agree better with each other, an expected result and also detected for other satellite data (August et al., 2012; Martin et al., 2019).

Comparison with SEVIRI shows a consistent negative bias during the night when compared to Tann, Teumetsat and Tera5. Several studies (e.g., Garand, 2003; Zheng et al., 2012) already reported cold biases between SEVIRI and other $T_{\text {skin }}$ products. For the ECMWF model, the cold bias over land was identified for a previous version of the model by Trigo and Viterbo (2003) and for a more recent version by Trigo et al. (2015). A misrepresentation of surface energy fluxes, either because of deficiencies in the parameterization of aerodynamic resistances, or in the partitioning between latent and sensible heat fluxes are frequent causes of these deviations (Trigo et al., 2015). The EUMETSAT Tskin product seem to agree the least with SEVIRI both during the day and the night, similar to what was reported by August et al., 2012. The standard deviation is the largest during the day, since the comparison is affected by the different Sun-surface-instrument geometries. Shadows due to orography or vegetation for example change in daytime with varying SEVIRI and Metop scan angle (August et al., 2012).

We also use station data for June 2016 for validating the $T_{\text {ANN }}$ product. This site is chosen in order to minimize complications from spatial scale mismatch between ground-based and satellite sensors. IASI cloud-free data was co-localized in space and time (within 1 minute of the station data). The spatial matching is done around $0.5^{\circ}$ of a validation site $\left[15.17^{\circ} \mathrm{E}, 23.18^{\circ} \mathrm{S}\right]$ which location is shown in shown in panel (a). This validation location was chosen because it is close of the station site and is representative of the same gravel plain surface, yet, away from the sand dunes limiting the station. The location of the station and the corresponding IASI 
observations is shown in Figure 7, panel (a). The total number of coincident IASI data points around this area is 82 . The validation of the $T_{\text {ANN }}$ with in-situ $T_{\text {skin }}$ is shown in Figure 7 panels (b), (c) and (d).

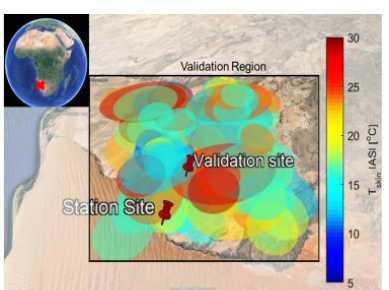

(a)

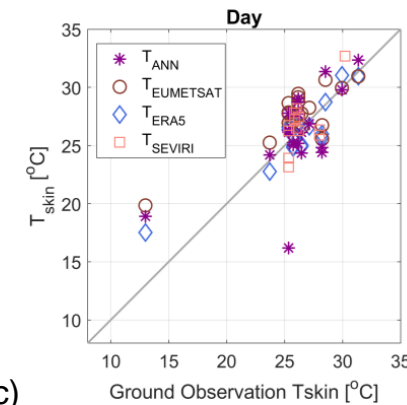

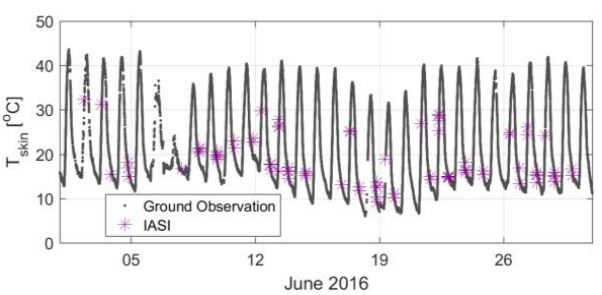

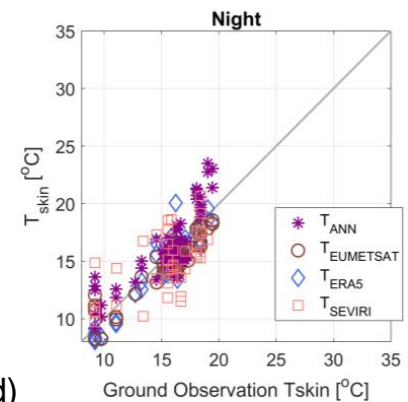

Figure 7: Comparison of IASI TANN with ground observations at Gobabeb: (a) station location and the 82 coincident IASI observations in June 2016 around the validation site chosen so all IASI observations fall in the gravel plains; (b) Diurnal variation of $T_{\text {skin; }}$ (c) $T_{\text {ANN versus in-situ }} \mathrm{T}_{\text {skin }}$ during the day; and (d) during the night.

Panel (b) of Figure 7 shows the strong diurnal variation of $T_{\text {skin }}$ observed at Gobabeb. The IASI data are either from the morning ( 9-10 am depending on the satellite swath) or evening overpass ( 9-10 pm): they are therefore always separated by $\sim 12$ hours.

Day and night correlation coefficients are $>0.9$. Table 2 lists how the different datasets used for validation compare to ground measurements. During the day, $T_{\text {ANN }}$ agrees the least with the station data, driven by the one point in Figure 7 panel (c) that has the largest bias. At night, TANN comparison with ground measurements is better, so is the comparison with other datasets, as also seen in Figure 7. Absolute biases mostly range between 0 and $2 \mathrm{~K}$, which is similar to the $T_{\text {skin }}$ spatial variability around Gobabeb station determined with detailed measurements carried by Goettsche et al. (2013). Comparison with other satellite measurements shows a general bias between -2 and 5 kelvins in summer months (Martin et al., 2019).

Table 2. Correlation coefficient, standard deviation, and absolute relative bias (\%), between ground based $T_{\text {skin }}$ and the different datasets used in this study 


\begin{tabular}{|l|l|l|l|l|}
\hline & $\begin{array}{c}\text { Standard } \\
\text { deviation }\left[{ }^{\circ}\right]\end{array}$ & $\begin{array}{c}\text { Absolute bias } \\
{\left[{ }^{\circ}\right]}\end{array}$ & $\begin{array}{c}\text { Standard } \\
\text { deviation }\left[{ }^{\circ}\right]\end{array}$ & $\begin{array}{c}\text { Absolute bias } \\
{\left[{ }^{\circ}\right]}\end{array}$ \\
\hline TANN - ground & 3.12 & 2.14 & 1.67 & 1.41 \\
\hline TEUMETSAT - ground & 1.99 & 2.03 & 1.00 & 1.06 \\
\hline TERA5 - ground & 1.57 & 1.18 & 1.06 & 1.01 \\
\hline TSEVIRI - ground & 1.67 & 1.50 & 2.45 & 2.09 \\
\hline
\end{tabular}

\subsection{Validation of the $T_{A N N}$ obtained from the EUMETSAT neural network}

The validation presented hereafter is similar to what was shown in Figures 5, 6, and 7 , and the discussion used for the discussion of the biases in those figures applies here too. Since the TANN validated here is derived from the EUMETSAT L2 product, it compares best with it as it is seen in Figure 8 .
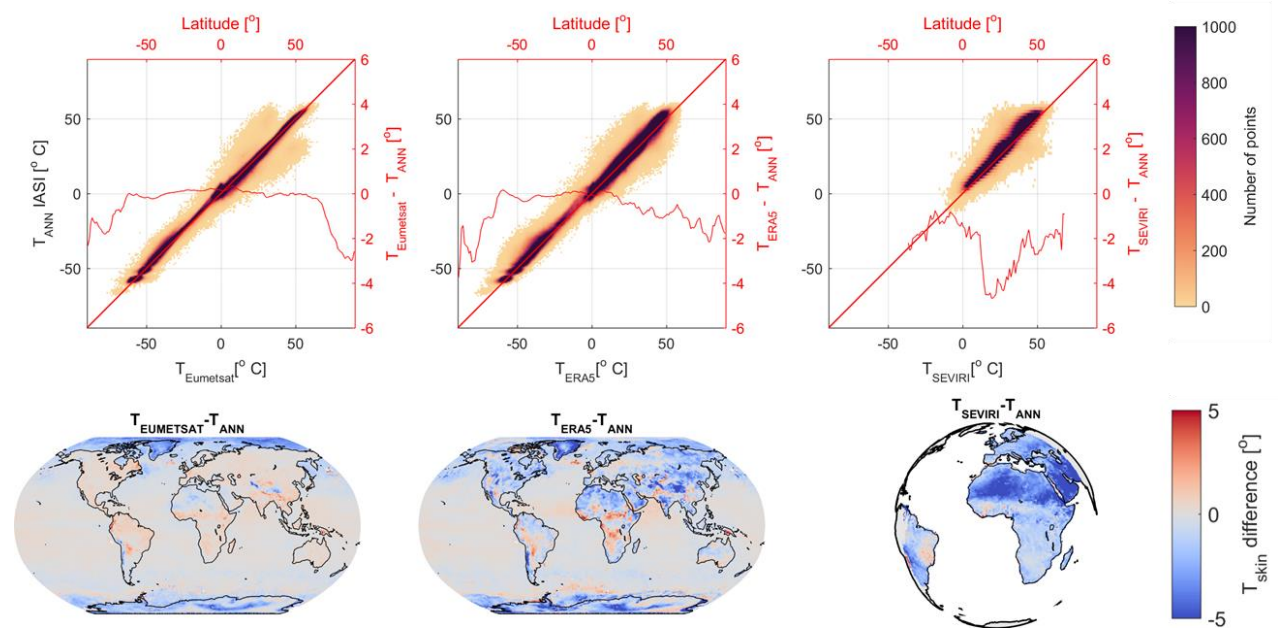

Figure 8. Same as Figure 5 but for $T_{\text {ANN }}$ derived from the EUMETSAT $T_{\text {skin }}$ neural network. For day + night observation: $\sigma\left(T_{\text {EUMETSAT }}-\mathrm{T}_{\text {ANN }}\right)=1.56, \sigma$ (TERA5 - TANN $\left._{\text {An }}\right)$ $=2.41, \sigma\left(T_{\text {SEVIRI }}-T_{\text {ANN }}\right)=3.67$. The total number of points for the global comparison is $8.2 \times 10^{6}$ points and $4.96 \times 10^{5}$ for the SEVIRI comparison.

Figure 9 is derived from data used in Figure 8, but separated into day and night, and includes the inter-comparison of the different products with each other. The $y$-axis limit is kept the same as in Figure 6 for quick comparisons. Again, TANN in this case agrees best with the EUMETSAT product, but also shows a similar good performance when compared to other datasets. 

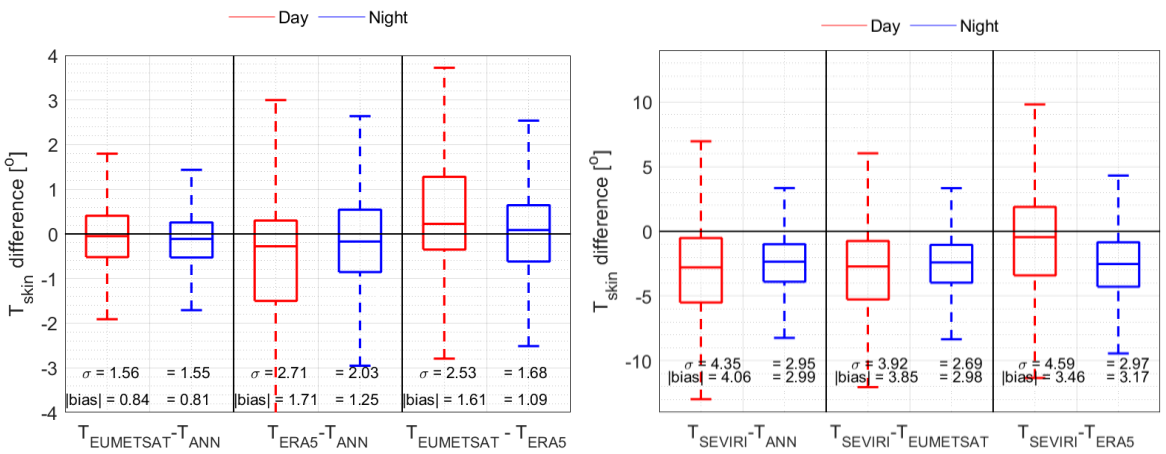

Figure 9: Boxplot of the June 2016 inter-comparison of the different $T_{\text {skin }}$ products used in this study. Since the matching with SEVIRI leads to fewer co-localized data points covering the SEVIRI disk, they are shown on a separate figure on the right. The central mark indicates the median, and the bottom and top edges of the box indicate the 25 th and 75 th percentiles.

Finally, comparison with ground observation in Figure 10 shows a better performance of TANN than what was presented in Figure 6 . Table 3 hereafter details the day and night biases where we can see that the $T_{\text {ANN }}$ in this case agrees better with ground measurements that what we presented in Table 2.
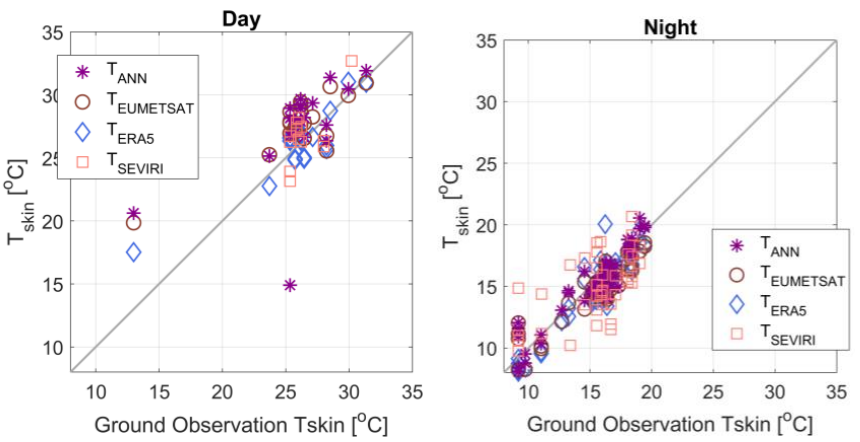

Figure 10: Comparison of IASI TANN derived from EUMETSAT neural network with ground observation at Gobabeb. Left panel: day, right panel: night. 
Table 3. Correlation coefficient, standard deviation, and absolute relative bias (\%), between ground based $T_{\text {skin }}$ and the different datasets used in this study

\begin{tabular}{|l|c|l|l|l|}
\hline \multirow{2}{*}{} & \multicolumn{2}{|c|}{ Day } & \multicolumn{2}{c|}{ Night } \\
\cline { 2 - 6 } & $\left.\begin{array}{c}\text { Standard } \\
\text { deviation [ }\end{array}{ }^{\circ}\right]$ & $\begin{array}{c}\text { Absolute bias } \\
{\left[^{\circ}\right]}\end{array}$ & $\begin{array}{c}\text { Standard } \\
\text { deviation }\left[{ }^{\circ}\right]\end{array}$ & $\begin{array}{c}\text { Absolute bias } \\
{\left[{ }^{\circ}\right]}\end{array}$ \\
\hline TANN - ground & 3.37 & 2.61 & 1.05 & 0.85 \\
\hline TEUMETSAT - ground & 1.99 & 2.04 & 1.00 & 1.06 \\
\hline TERA5 - ground & 1.57 & 1.18 & 1.06 & 1.01 \\
\hline TSEVIRI - ground & 1.67 & 1.50 & 2.45 & 2.09 \\
\hline
\end{tabular}

\section{Discussion and Conclusions}

Satellite data are able to provide systematic global temperature data, at least in cloud-free areas, from pole to pole on a regular basis. EUMETSAT has been updating different versions of algorithms to retrieve the skin temperature from IASI, and at the same time, relying on different instruments (particularly for cloudy scenes) to derive a $T_{\text {skin }}$ product. Consequently, no homogenous consistent IASI Tskin record exists to date. In this study, we derive a Tskin product using Metop-A IASI L1C radiances. The first challenge is to find the channels with access to surface information. To this end, we present a method based on entropy reduction, to find the channels with the highest information content in skin temperature. An efficient and fast IASI retrieval algorithm based on artificial neural networks is then used to calculate $T_{\text {skin }}$ from the upwelling IASI radiances. While empirical methods using ANN can deal with hundreds to thousands of channels (Aires et al., 2002), we show in this study how ANN and channel selection can be used to retrieve Tskin, making this method fast and reliable for near real-time application, as well as to reprocess more than 11 years of IASI data. In this study, we perform two ANN trainings in 2018 with IASI radiances as input and we use two distinct datasets for two separate trainings. In the first, a dedicated ERA5 12-minute simulation is used as output, and in the second EUMETSAT L2 data is used as output. Each of the resulting neural networks is then applied for a different year (2016) and validated. Our results show the potential of ANN in mapping radiances globally and locally to skin temperature. We show how both neural networks perform similarly well when compared to other datasets, with the EUMETSAT-derived network performing better (in particular during nighttime) when it is compared to ground station $T_{\text {skin. }}$ To compare the two products obtained from the two neural networks, we show in Figure 11 the daily variation of the skin temperature in 2017, for the Northern Hemisphere in the left panel and the Southern Hemisphere in the right panel. Generally, all datasets agree well with one another, with $\mathrm{T}_{\mathrm{ANN}}$ obtained from the ERA5 $\mathrm{T}_{\text {skin }}$ product closer to the latter (which is expected) same as $T_{A N N}$ obtained from the EUMETSAT L2 $T_{\text {skin }}$ product is closer to the actual EUMETSAT Tskin product. 

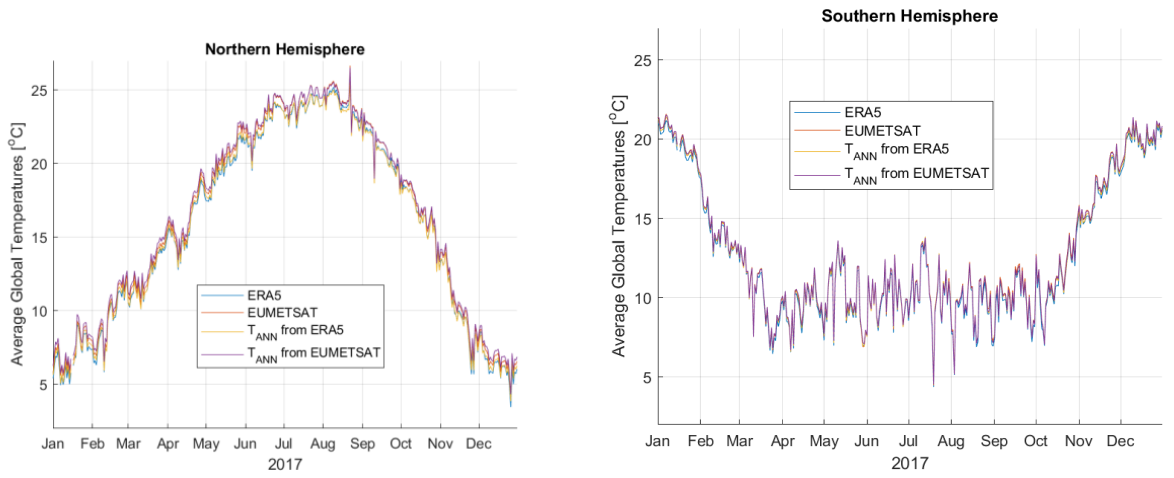

609

610

Figure 11. Daily averaged $T_{\text {skin }}$ from the different global datasets used (ERA5 and EUMETSAT L2) and produced (TANN obtained from ERA5 and EUMETSAT L2) in this study.

More generally, retrieval of $T_{\text {skin }}$ from space measurements faces many challenges. First, the $T_{\text {skin }}$ calculation from the radiance within the radiative transfer equation is an ill-posed problem. The solution of the radiative transfer equation requires the simultaneous knowledge of two unknowns: $T_{\text {skin }}$ and the surface emissivity. This is generally solved with the assumption of a good initial guess to constrain the solution (Aires et al., 2001; Paul et al., 2012) and a rapid and accurate direct transfer model (Rodgers, 1976). Since the observed radiance spectra are affected by the surface properties, using it as input to the ANN takes emissivity knowledge into account. Second, infrared retrievals are only available under clear-sky conditions, reducing the amount of global data by roughly one third. This study has been performed with data from IASI on Metop A, and it implies that with IASI on Metop B and Metop C, the global coverage can be enhanced.

Third, validation and inter-comparison between different products are challenges that not only bound to this study. The diversity in sensor characteristics and sensorspecific skin temperature retrieval algorithms, as well as the different challenges facing current NWP models, make it difficult to homogenize different skin temperature products for proper comparison. Moreover, for polar-orbiting satellite products, intercomparison between different $T_{\text {skin }}$ satellite products is challenging since the crossing times of the satellites, and the shape of the field of view are different. For example, MODIS (with overpass time at 10:30 am/pm on TERRA) and MODIS and AIRS, on the AQUA platform (with an overpass time of $1: 30 \mathrm{am} / \mathrm{pm}$ ), both offer a good skin temperature product. IASI on the other hand, has an overpass time of 9:30 am/pm local-time. Since skin temperature, particularly over the land surfaces vary strongly in space and time (Prata et al., 1995), inter-comparison between IASI and MODIS or AIRS, with a time difference of 1 to more than 4 hours can imply a difference of the order of 10 degrees or more in some regions. This makes inter-comparison with other satellite products with different crossing time very difficult to achieve. Moreover, considering IASI's pixel area to be a circle of $\pi \times 12 \times 12 \mathrm{~km}^{2}$ at nadir and an ellipse 
with an area up to $\pi \times 20 \times 39 \mathrm{~km}^{2}$ at its outermost viewing angle of $48^{\circ}$ (off-nadir), several surface types with varying skin temperature and emissivities will co-exist within one pixel. The resulting skin temperature is therefore an "effective" measure of the average of the surface-heterogeneity existing in the pixel. This alone complicates the physical understanding of the $T_{\text {skin }}$ values retrieved from space from different instruments with different pixel shapes (round/ellipse vs square/rectangle, etc.), and sizes. Moreover, the satellite viewing angle also a role in the $T_{\text {skin }}$ at the surface: the comparison is affected by the different Sun-surface-instrument geometries, as a result of shadows due to orography or vegetation for example (August et al., 2012). Finally, the scarcity of in situ $T_{\text {skin }}$ ground-observations impedes proper validation, which in turn is difficult to be properly performed since ground observation is usually taken at one specific location and time. Given that $T_{\text {skin }}$ might strongly change within short distances (less than a meter, Li et al., 2013), co-locating a satellite measurement with a ground observation, as we attempted in section 3.3, might undergo similar large differences as well. Here, a comparison was made at a station located in a homogenous area to overcome this problem.

Using channel selection and artificial neural network, this work shows a $T_{\text {skin }}$ retrieval method that can serve as a baseline for constructing the first homogeneous dataset of skin temperature from IASI, and can be extended to other infrared remote measurements. Future work will look at constructing a $T_{\text {skin }}$ time series from IASI during 2007-present and using Metop A, B, and C for climate trends application. Regional and seasonal variations can be studied using the atlas for the surface skin temperature distributions. The daily/monthly/yearly variations will be studied in terms of the main climate drivers (solar, volcanic eruptions, aerosols and greenhouse gases) and modes of variability at the inter-annual and decadal timescales.

\section{Data availability}

The IASI Level 1C data for 2018 are distributed in near real time by Eumetsat through the EumetCast system distribution. The reprocessed Metop-A L1C data used in this study for June 2016 will be available in summer 2019 (doi: 10.15770/EUM_SEC_CLM_0014). The EUMETSAT L2 data used in this study can be retrieved from the Aeris data infrastructure (https://www.aeris-data.fr/). ERA5 data is provided by ECMWF and can be retrieved at http://www.ecmwf.int or https://cds.climate.copernicus.eu/. The 12-minute simulation output used in this work can be obtained by contacting the lead author (sarah.safieddine@latmos.ipsl.fr). The hourly LST data derived from SEVIRI/Meteosat are freely available from http://landsaf.ipma.pt within the context of the LSA SAF project funded by EUMETSAT. The ground observation data can be obtained by contacting F.G. (frank.goettsche@kit.edu).

\section{Author contribution}

S.S. wrote the paper with comments from the rest of the co-authors and performed the neural network calculation and validation. A.P. provided the ERA5/IASI data 
matching, M.G. provided data for the ANN training, F.A. and V.P. provided the codes for the channel selection using the ER method, L.C. and S.W. helped in conceptualizing the neural network approach, O.L. provided data for Figure 1, J.N.T, H.H, and G.R. provided the 12-minute ERA5 fields, F.G. and M.M. provided ground measurement data. M. D.-B., D. C. and T. A. helped with the IASI L1C retrieval. C.C. supervised this work and helped with the conceptualization of the study.

\section{Competing interests}

The authors declare that they have no conflict of interest.

\section{Acknowledgments}

The authors thank J. Hadji-Lazaro, J.M. Sabater, C. Jimenez, I. Trigo, C.F. Barroso, and P. Kasibhatla for useful discussions. This work was supported by the CNES. It is based on observations with IASI embarked on Metop. The authors acknowledge the Aeris data infrastructure (https://www.aeris-data.fr/) for providing access to the IASI Level $1 \mathrm{C}$ data and Level 2 temperature data used in this study. The LST validation site is supported by the Satellite Application Facility (SAF) on Land Surface Analysis (LSA), a European project initiated and financed by EUMETSAT. This project has received funding from the European Research Council (ERC) under the European Union's Horizon 2020 and innovation programme (grant agreement No 742909).

\section{References}

Aires, F., Prigent, C., Rossow, W.B., and Rothstein, M.: A new neural network approach including first-guess for retrieval of atmospheric water vapor, cloud liquid water path, surface temperature and emissivities over land from satellite microwave observations, Journal of Geophysical Research, Vol. 106, D14, pp. 14,887-14,907, 2001.

Aires, F., Pellet, V., Prigent, C., Moncet, J.-L. : Dimension reduction of satellite observations for remote sensing, Part I: A comparison of compression, channel selection, and bottleneck channel approaches, Q. J. R. Meteorol. Soc., 142: 2658-2669, doi:10.1002/aj.2855, 2016.

Aires, F., Chédin, A., Scott, N. A., Rossow, W. B.: A regularized neural net approach for retrieval of atmospheric and surface temperatures with the IASI instrument, Journal of Applied Meteorology, 41, pp. 144-159, 2002.

August, T., Klaes, D., Schlüssel, P., Hultberg, T., Crapeau, M., Arriaga, A., O'Carroll, A., Coppens, D., Munro, R., and Calbet, X.: IASI on Metop-A: Operational Level 2 retrievals after five years in orbit, J. Quant. Spectrosc. Ra., 113, 1340-1371, https://doi.org/10.1016/j.jqsrt.2012.02.028, 2012. 
Becker, F., and Li, Z.-L.: Surface temperature and emissivity at various scales: Definition, measurement and related problems, Remote Sensing Reviews, 12, 225-253, 1995.

Blackwell, W. J., and Chen, F. W.: Neural Networks in Atmospheric Remote Sensing Artech House Massachusetts Institute of Technology, Cambridge Massachusetts, 2009.

Blumstein, D., Chalon, G., Carlier, T., Buil, C., Hebert, P., Maciaszek, T., Ponce, G., Phulpin, T., Tournier, B., and Simeoni, D.: IASI instrument: Technical Overview and measured performances, SPIE Denver, 5543-22, 2004

Brindley, H., Bantges, R., Russell, J., Murray, J., Dancel, C., Belotti, C., and Harries, J.: Spectral Signatures of Earth's Climate Variability over 5 Years from IASI, J. Climate, 28, 1649-1660, doi:10.1175/JCLI-D-14-00431.1, 2015.

Brindley, H., and Bantges, R.: The Spectral Signature of Recent Climate Change, Curr Clim Change Rep 2: 112. https://doi.org/10.1007/s40641-016-0039-5, 2016.

Copernicus Climate Change Service (C3S): ERA5: Fifth generation of ECMWF atmospheric reanalyses of the global climate. Copernicus Climate Change Service Climate Data Store (CDS), last accessed 11/04/2019, https://cds.climate.copernicus.eu/cdsapp\#!/home, 2017.

Chevallier, F., Chéruy, F., Scott, N. A., and Chédin, A.: A Neural Network Approach for a Fast and Accurate Computation of a Longwave Radiative Budget, J. Appl. Meteor., 37, 1385-1397, 1998.

Clarisse, L., R'Honi, Y., Coheur, P.-F., Hurtmans, D., and Clerbaux, C.: Thermal infrared nadir observations of 24 atmospheric gases, Geophys. Res. Lett., 38, L10802, doi:10.1029/2011GL047271, 2011.

Clerbaux, C., Hadji-Lazaro, J., Turquety, S., Mégie, G., and Coheur, P.-F.: Trace gas measurements from infrared satellite for chemistry and climate applications, Atmos. Chem. Phys., 3, 1495-1508, https://doi.org/10.5194/acp-3-1495-2003, 2003.

Clerbaux, C., Boynard, A., Clarisse, L., George, M., Hadji-Lazaro, J., Herbin, H., Hurtmans, D., Pommier, M., Razavi, A., Turquety, S., Wespes, C., and Coheur, P.-F.: Monitoring of atmospheric composition using the thermal infrared IASI/MetOp sounder, Atmos. Chem. Phys., 9, 6041-6054, doi:10.5194/acp-96041-2009, 2009.

Clerbaux, C., and Crevoisier, C.: New Directions: Infrared remote sensing of the troposphere from satellite: Less, but better, Atmospheric Environment, 72, 24-26, doi: 10.1016/j.atmosenv.2013.01.057, 2013. 
Clerbaux, C., Hadji-Lazaro, J., Turquety, S., George, M., Boynard, A., Pommier, M., Safieddine, S. Coheur, P.-F., Hurtmans, D., Clarisse, L., and Van Damme, M., Tracking pollutants from space: Eight years of IASI satellite observation, C. R. Geosci., doi:10.1016/j.crte.2015.06.001, 2015.

Coheur, P.-F., Clarisse, L., Turquety, S., Hurtmans, D., and Clerbaux, C.: IASI measurements of reactive trace species in biomass burning plumes, Atmos. Chem. Phys., 9, 5655-5667, https://doi.org/10.5194/acp-9-5655-2009, 2009.

Collard, A. D.: Selection of IASI channels for use in numerical weather prediction, Q. J. R. Meteorol. Soc., 133(629):1977-1991, 2007.

Collard, A.D., and McNally, A. P.: The assimilation of Infrared Atmospheric Sounding Interferometer radiances at ECMWF, Q. J. Roy. Meteorol. Soc., 135, 1044-1058, 2009.

Crevoisier, C., Clerbaux, C., Guidard, V., Phulpin, T., Armante, R., Barret, B., CamyPeyret, C., Chaboureau, J.-P., Coheur, P.-F., Crépeau, L., Dufour, G., Labonnote, L., Lavanant, L., Hadji-Lazaro, J., Herbin, H., Jacquinet-Husson, N., Payan, S., Péquignot, E., Pierangelo, C., Sellitto, P., and Stubenrauch, C.: Towards IASI-New Generation (IASI-NG): impact of improved spectral resolution and radiometric noise on the retrieval of thermodynamic, chemistry and climate variables, Atmos. Meas. Tech., 7, 4367-4385, https://doi.org/10.5194/amt-74367-2014, 2014.

ECMWF, IFS DOCUMENTATION - Cy43r1 Operational implementation 22 Nov 2016 part IV: physical processes, 2016.

EUMETSAT, IASI Level 1: Product Guide, 19 September 2017, EUM/OPSEPS/MAN/04/0032, http://www.eumetsat.int/website/wcm/idc/idcplg?ldcService=GET FILE\&dDocNa me=PDF DMT 151562\&RevisionSelectionMethod=LatestReleased\&Rendition= Web, 2017a.

EUMETSAT, IASI Level 2: Product Guide, 11 July 2017, EUM/OPS-EPS/MAN/04/0033, http://www.eumetsat.int/website/wcm/idc/idcplg?ldcService=GET FILE\&dDocNa me=PDF DMT 151563\&RevisionSelectionMethod=LatestReleased\&Rendition= Web , 2017b.

Freitas, S. C., Trigo, I. F., Bioucas-Dias, J. M., Goettsche, F.-M.: Quantifying the Uncertainty of Land Surface Temperature Retrievals From SEVIRI/Meteosat, IEEE Trans. Geosci. Remote Sens. DOI: 10.1109/TGRS.2009.2027697, 2010. 
Garand, L.: Toward an integrated land-ocean surface skin temperature analysis from the variational assimilation of infrared radiances, J. Appl. Meteorol., 42, 570-583, doi:10.1175/1520-0450(2003)042<0570:TAILSS>2.0.CO;2, 2003.

GCOS : Report Of The Twenty-Fifth Session Of The WMO-IOC-UNEP-ICSU Steering Committee For GCOS, World Meteorological Organization, Geneva, Switzerland, accessed at https://library.wmo.int/doc num.php?explnum id=4118, (last access 18/03/2019), 2017.

Goldberg, M. D., Qu, Y. N., McMillin, L. M., Wolf, W., Zhou, L. H., Divakarla, M.: AIRS near-real-time products and algorithms in support of operational numerical weather prediction. IEEE Trans. Geosci. Remote Sens.;41:379-389, doi: 10.1109/TGRS.2002.808307, 2003.

Good, E. J.: An in situ-based analysis of the relationship between land surface "skin" and screen-level air temperatures, J. Geophys. Res. Atmos., 121, 8801-8819, doi: 10.1002/2016JD025318, 2016.

Göttsche, F. M., and Hulley, G. C.: Validation of six satellite-retrieved land surface emissivity products over two land cover types in a hyper-arid region, Remote Sensing of Environment, 124, 149-158, https://doi.org/10.1016/i.rse.2012.05.010, 2012.

Göttsche, F. -M., Olesen, F. -S., and Bork-Unkelbach, A.: Validation of land surface temperature derived from MSG/SEVIRI with in situ measurements at Gobabeb, Namibia, International Journal of Remote Sensing, 34(9-10), 3069-3083, 2013.

Göttsche, F. M., Olesen, F., Trigo, I., Bork-Unkelbach, A., and Martin, M.: Long term validation of land surface temperature retrieved from MSG/SEVIRI with continuous in-situ measurements in Africa, Remote Sensing, 8(5), 410. https://doi.org/10.3390/rs8050410, 2016.

Hadji-Lazaro, J., Clerbaux, C., and Thiria, S.: An inversion algorithm using neural networks to retrieve atmospheric $\mathrm{CO}$ total columns from high-resolution nadir radiances, Journal of Geophysical Research: Atmospheres, 104 (D19), 790 23841-23854. doi: 10.1029/1999jd900431,1999.

Hersbach, H. and Dee, D.: ERA5 reanalysis is in production, ECMWF Newsletter, 147, https://www.ecmwf.int/en/newsletter/147/news/ era5-reanalysis-production (last access: 21/01/2019), 2016.

Hersbach, H., de Rosnay, P., Bell, B., Schepers, D., Simmons, A., Soci, C., Abdalla, S., Alonso-Balmaseda, M., Balsamo, G., Bechtold, P., Berrisford, P., Bidlot, J.R., de Boisséson, E., Bonavita, M., Browne, P., Buizza, R., Dahlgren, P., Dee, D., Dragani, R., Diamantakis, M., Flemming, J., Forbes, R., Geer, A. J., Haiden, T., Hólm, E., Haimberger, L., Hogan, R., Horányi, A., Janiskova, M., Laloyaux, P., Lopez, P., Munoz-Sabater, J., Peubey, C., Radu, R., Richardson, D., Thépaut, J.-N., Vitart, F., Yang, X., Zsótér, E., Zuo, H. : Operational global 
reanalysis: progress, future directions and synergies with NWP, ERA Report Series, last access 04/11/2019, https://www.ecmwf.int/en/elibrary/18765operational-global-reanalysis-progress-future-directions-and-synergies-nwp, 2018.

Hirahara, S., Alonso-Balmaseda, M., de Boisseson, E. and Hersbach, H: Sea Surface Temperature and Sea Ice Concentration for ERA5, ERA Report Series, 26, https://www.ecmwf.int/en/elibrary/16555-sea-surface-temperature-and-seaice-concentration-era5 (last access: 05/04/2019), 2016.

Hilton, F., Armante, R., August, T., Barnet, C., Bouchard, A., Camy-Peyret, C., Capelle, V., Clarisse, L., Clerbaux, C., Coheur, P.-F., Collard, A., Crevoisier, C., Dufour, G., Edwards, D., Faijan, F., Fourrié, N., Gambacorta, A., Goldberg, M., Guidard, V., Hurtmans, D., Illingworth, S., Jacquinet-Husson, N., Kerzenmacher, T., Klaes, D., Lavanant, L., Masiello, G., Matricardi, M., McNally, A., Newman, S., Pavelin, E., Payan, S., Péuignot, E., Peyridieu, S., Phulpin, T., Remedios, J., Schlüssel, P., Serio, C., Strow, L., Stubenrauch, C., Taylor, J., Tobin, D., Wolf, W., and Zhou, D.: Hyperspectral Earth Observation from IASI: Five Years of Accomplishments, Bull. Am. Meteorol. Soc., 93, 347-370, doi:10.1175/BAMS-D11-00027.1, 2012.

Jin, M.: Analysis of land skin temperature using AVHRR observations, Bull. Amer. Meteor. Soc., 85, 587-600, 2004.

Klaes, D., Cohen, M., Buhler, Y., Schlüssel, P., Munro, R., Luntama, J.-P., von Engeln, A., O'Clerigh, E., Bonekamp, H., Ackermann, J., and Schmetz, J.: An Introduction to the EUMETSAT Polar system, B. Am. Meteorol. Soc., 88, 10851096, doi:10.1175/BAMS-88-7-1085, 2007.

Li, Z.-L., Tang, B.-H., Wu, H., Ren, H., Yan, G., Wan, Z., Trigo, I. F., and Sobrino, J. A.: Satellite-derived land surface temperature: Current status and perspectives, Remote Sens. Environ., 131, 14-37, 2013.

Martin, M. A., Ghent, D., Cordeiro Pires, A., Göttsche, F.-M., Cermak, J., Remedios, J. J.: Comprehensive In Situ Validation of Five Satellite Land Surface Temperature Data Sets over Multiple Stations and Years, Remote Sens. 11(5), 479; doi:10.3390/rs11050479, 2019.

McLaren, A., Fiedler, E., Roberts-Jones, J., Martin, M., Mao, C., Good, S.: Quality Information Document Global Ocean OSTIA Near Real Time Level 4 Sea Surface Temperature Product SST-GLO-SST-L4-NRT-OBSERVATIONS-010001, EU Copernicus Marine Service, 2016. 
McKeown, W., Bretherton, F., Huang, H. L., Smith, W. L., and Revercomb, H. L.: Sounding the skin of water: Sensing air/water interface temperature gradients with interferometry, J. Atmos. Ocean. Tech., 12, 1313-1327, 1995.

Moncet, J.-L., Uymin, G., Lipton, A. E., and Snell, H. E.: Infrared radiance modeling by optimal spectral sampling. J. Atmos. Sci., 65, 3917-3934, doi:10.1175/2008JAS2711.1, 2008.

Paul, M., Aires, F., and Prigent, C.: An innovative physical scheme to retrieve simultaneously surface temperature and emissivities based on a high-resolution infrared emissivity interpolator, J. of Geophys. Res., 117, D11302, doi: 10.1029/2011JD017296, 2012.

Pellet, V., and Aires, F.: Dimension reduction of satellite observations for remote sensing, Part II: Illustration using hyper-spectral microwave observations, Q.J.R. Meteorol. Soc., 142: 2670-2678, doi:10.1002/ai.2857, 2016.

Pellet, V. and Aires, F.: Bottleneck Channels Algorithm for Satellite Data Dimension Reduction: A Case Study for IASI, IEEE Transactions on Geoscience and Remote Sensing, vol. 56, no. 10, pp. 6069-6081, doi: 10.1109/TGRS.2018.2830123, 2018.

Prata, A. J., Caselles, V., Colland, C., Sobrino, J. A. and Ottle, C.: Thermal remote sensing of land surface temperature from satellites: current status and future prospects Remote Sens. Rev., 12 175-224, 1995.

Prigent, C., Aires, F., and Rossow, W. B.: Land surface skin temperatures from a combined analysis of microwave and infrared satellite observations for an allweather evaluation of the differences between air and skin temperatures, Journal of Geophysical Research, 108, no. D10, 4310, doi:10.1029/2002JD002301, 2002.

Prigent C., Aires, F., and Rossow, W.B.: Retrieval of surface and atmospheric geophysical variables over snow-covered land from combined microwave and infrared satellite observations. J. Appl. Meteorol., 42, 368-380, doi:10.1175/15200450(2003)042<0368:ROSAAG>2.0.CO;2, 2003.

Rabier, F., Fourrie, N., Chafai, D., and Prunet, P.: Channel selection methods for Infrared Atmospheric Sounding Interferometer radiances, Q. J. R. Meteorol. Soc., 128, 1011-1027, 2002.

Rhee, J., Im J., Carbone, G.J.: Monitoring agricultural drought for arid and humid regions using multi-sensor remote sensing data, Remote Sens. Environ., 114:2875-2887, doi: 10.1016/j.rse.2010.07.005, 2010.

Rodgers, C. D.: Retrieval of atmospheric temperature and composition from remote measurements of thermal radiation, Rev. Geophys. Space Phys., 14, 609-624, 1976. 
Rodgers, C. D: Information content and optimisation of high spectral resolution measurements, Proc SPIE, 1996.

Rodgers, C. D.: Inverse methods for atmospheric sounding - Theory and practise, edited by: Taylor, F. W., World Scientific, Singapore, 2000.

Ruzmaikin, A., Aumann, H. H., Lee, J., and Susskind, J.: Diurnal cycle variability of surface temperature inferred from AIRS data, Journal of Geophysical Research: Atmospheres, 122, 10,928-10,938. https://doi.org/10.1002/2016JD026265, 2017.

Saunders, R., Hocking, J., Turner, E., Rayer, P., Rundle, D., Brunel, P., Vidot, J., Roquet, P., Matricardi, M., Geer, A., Bormann, N., and Lupu, C.: An update on the RTTOV fast radiative transfer model (currently at version 12), Geosci. Model Dev., 11, 2717-2737, https://doi.org/10.5194/gmd-11-2717-2018, 2018.

Schmetz, J., Pili, P., Tjemkes, S., Just, D., Kerkmann, J., Rota, S., Ratier, A: An introduction to Meteosat Second Generation (MSG), Bull. Am. Meteorol. Soc. 83, 992-992, 2002.

Siméoni, D., Singer, C., Chalon, G.: Infrared atmospheric sounding interferometer, Acta Astronautica, 40, 113-118, doi:10.1016/S0094-5765(97)00098-2, 1997.

Smith, N., Smith, W. L., Weisz, E., and Revercomb, H. E.: AIRS, IASI, and CrIS Retrieval Records at Climate Scales: An Investigation into the Propagation of Systematic Uncertainty, J. Appl. Meteor. Climatol., 54(7), 1465, 1481, doi: 10.1175/JAMC-D-14-0299.1., 2015.

Susskind, J., Schmidt, G. A., Lee, J. N., and Iredell, L.: Recent global warming as confirmed by AIRS, Environ. Res. Lett. 14 044030, https://doi.org/10.1088/17489326/aafd4e, 2019.

Trigo, I. F., and Viterbo, P.: Clear-Sky Window Channel Radiances: A Comparison between Observations and the ECMWF Model. J. Appl. Meteor., 42, 1463-1479, https://doi.org/10.1175/1520-0450 (2003)042<1463:CWCRAC>2.0.CO;2, 2003.

Trigo, I. F., Peres, L. F., DaCamara, C. C., and Freitas, S. C.: Thermal Land Surface Emissivity Retrieved From SEVIRI/Meteosat, IEEE Transactions on Geoscience and Remote Sensing, vol. 46, no. 2, pp. 307-315, doi: 10.1109/TGRS.2007.905197, 2008.

Trigo, I. F., Dacamara, C. C., Viterbo, P., Roujean, J.-L., Olesen, F., Barroso, C., Camacho-de Coca, F., Carrer, D., Freitas, S. C., García-Haro, J., Geiger, B., Gellens-Meulenberghs, F., Ghilain, N., Meliá, J., Pessanha, L., Siljamo, N., and Arboleda, A.: The Satellite Application Facility for Land Surface Analysis, Int. J. Remote Sens., 32, 2725-2744,doi:10.1080/01431161003743199, 2011.

Trigo, I., Boussetta, S., Viterbo, P., Balsamo, G., Beljaars, A., and Sandu, I.: Comparison of model land skin temperature with remotely sensed estimates and 
assessment of surface-atmosphere coupling, J. Geophys. Res.-Atmos., 120, D023812, https://doi.org/10.1002/2015JD023812, 2015.

Van Damme, M., Whitburn, S., Clarisse, L., Clerbaux, C., Hurtmans, D., and Coheur, P.-F.: Version 2 of the IASI NH3 neural network retrieval algorithm: near-real-time and reanalysed datasets, Atmos. Meas. Tech., 10, 4905-4914, https://doi.org/10.5194/amt-10-4905-2017, 2017.

Ventress, L. and Dudhia, A.: Improving the selection of IASI channels for use in numerical weather prediction, Q. J. R. Meteorol. Soc., 140 (684): 2111-2118, 2014.

Wan, Z., and Li, Z-L.: A physics-based algorithm for retrieving land-surface emissivity and temperature from EOS/MODIS data, IEEE Trans. Geosci. Remote Sens., 35, 980-996, 1997.

Whitburn, S., Van Damme, M., Clarisse, L., Bauduin, S., Heald, C. L., Hadji-Lazaro, J., Hurtmans, D., Zondlo, M. A., Clerbaux, C., and Coheur, P.-F.: A flexible and robust neural network IASINH3 retrieval algorithm, J. Geophys. Res.-Atmos., 121, 6581-6599, https://doi.org/10.1002/2016jd024828, 2016.

Zheng, W., Wei, H., Wang, Z., Zeng, X., Meng, J., Ek, M., Mitchell, K., and Derber, J.: Improvement of daytime land surface skin temperature over arid regions in the NCEP GFS model and its impact on satellite data assimilation, J. Geophys. Res., 117, DO6117, https://doi.org/10.1029/2011JD015901, 2012.

Zhou, L., Dickinson, R. E., Tian, Y., Jin, M., Ogawa, K., Yu, H., Schmugge, T. A.: sensitivity study of climate and energy balance simulations with use of satellitederived emissivity data over northern africa and the arabian peninsula, J. Geophys. Res., 108 doi: 10.1029/2003JD004083, 2003. 